\title{
Dose relationship between oral glucocorticoids and tumor necrosis factor inhibitors and the risk of hospitalized infectious events among patients with rheumatoid arthritis
}

\author{
Jennifer Schenfeld ${ }^{1} \cdot$ Jan Iles $^{2} \cdot$ Mona Trivedi $^{2} \cdot$ Neil A. Accortt $^{2}$
}

Received: 16 September 2016 / Accepted: 7 February 2017 / Published online: 2 March 2017

(c) The Author(s) 2017. This article is published with open access at Springerlink.com

\begin{abstract}
The objective of this study was to evaluate the impact of oral glucocorticoid (GC) dose on rates of hospitalized infectious events (HIEs) among RA patients newly exposed to tumor necrosis factor inhibitor (TNFi) therapy. This retrospective cohort study used data from the MarketScan claims database. Incident and prevalent adult RA patients newly exposed to TNFi therapy were identified and assigned to three cohorts: no GC, low-dose GC $(\leq 7.5 \mathrm{mg})$, and high-dose GC (>7.5 mg); patients could contribute exposure time to multiple cohorts if they changed dose or discontinued GC. The primary outcome was estimated incidence rate (IR) of HIEs per 100 patient-years of GC exposure. A total of 40,933 eligible patients were identified (mean age 53.0 years; $77.4 \%$ female). HIE risk increased with increasing GC dose: the IR [95\% confidence interval (CI)] was 3.9 (3.63-4.13) for no GC; 6.4 (5.68-7.16) for low-dose GC; and 13.3 (11.9-15.5) for high-dose GC. Adjusted rate ratios (95\% CI) were 1.4 (1.21-1.60) for lowdose vs no GC; 2.8 (2.32-3.34) for high-dose vs no GC, and $2.0(1.66-2.45)$ for high-dose vs low-dose GC. The risk of HIEs increased with increasing age. HIE risk did not increase with longer exposure to GCs. Oral GCs, regardless of dose, significantly increased the risk of HIEs among RA patients newly initiating TNFi therapy. Steroid dosing must be considered when assessing infection risk in treatment decisions for RA patients.
\end{abstract}

Neil A. Accortt

naccortt@amgen.com

DOCS Global, Inc., North Wales, PA, USA

2 Amgen Inc., One Amgen Center Drive, Thousand Oaks, CA 91320, USA
Keywords Arthritis - Rheumatoid - Glucocorticoids · Infection $\cdot$ Hospitalization

\section{Introduction}

Rheumatoid arthritis (RA) is characterized by persistent inflammation in joints that leads to damage in the surrounding cartilage and bone. Patients with RA have been shown to be at increased risk for hospitalized infectious events (HIEs) compared to the general population [1, 2], and the risk increases with more severe disease [3]. A retrospective longitudinal study showed that the rate of infections requiring medical care among patients diagnosed with RA (19.6 cases per 100 person-years) was greater than the rate for patients without an RA diagnosis (12.9 cases per 100 person-years) [1]. In a retrospective study of HIEs, the adjusted hazard ratio (HR) for infection was 2.03 [95\% confidence interval (CI) 1.93-2.13] for patients with RA vs those without RA [2]. It is not clear if this increased risk is due to dysregulation of the immune system characteristic of inflammatory diseases.

Current therapies for the treatment of RA include many drugs that have immunosuppressive properties, such as tumor necrosis factor inhibitor (TNFi) medications and glucocorticoids (GCs). A prospective observational study found that patients with RA treated with a TNFi had $20 \%$ greater risk of serious infection (defined as requiring intravenous antibiotics or hospitalization or resulting in death) compared to patients with RA treated with nonbiologic disease-modifying antirheumatic drugs (DMARDs) (adjusted HR 1.2; 95\% CI 1.1-1.5) [4]. Notably, serious infections were infrequent in both groups, with rates of 42 and 32 serious infections per 1000 person-years in TNFi-treated and nonbiologic DMARD-treated patients, respectively. 
Studies have suggested that oral GCs further increase the risk of HIEs among patients with RA. Although definitions of low and high dose vary between studies, exposure to low-dose GCs has been shown to increase the risk of HIEs, and exposure to high-dose GCs further increased the risk of serious infection and HIEs [5-9]. The purpose of this study was to better understand the impact of concomitant use of GCs among RA patients who were newly exposed to TNFi therapy. We estimated the incidence rates (IRs) of HIEs based on exposure to TNFi medications (both collectively and individually) and to exposure to various levels of GCs. The hypothesis to be tested was that the rate of HIEs is higher among patients with RA on TNFi medications exposed to low-dose oral GCs as compared to patients on TNFi medications who are not exposed to oral GCs.

\section{Materials and methods}

\section{Study design and data source}

This was a retrospective cohort study that utilized the MarketScan Commercial and Medicare supplemental claims database from January 1, 2005 through June 30, 2014. The commercial database contains the inpatient, outpatient, and outpatient prescription drug experience of $\sim 40$ million employees and their dependents, who are covered under a variety of fee-for-service and managed care health plans. The Medicare database contains the healthcare experience of $\sim 3$ million retirees with Medicare supplemental insurance paid for by employers. Both databases contain detailed cost, use, and outcomes data for inpatient and outpatient healthcare services. The medical claims are linked to outpatient prescription drug claims and person-level enrollment data through the use of unique enrollee identifiers.

The index date was the first exposure to TNFi therapy (adalimumab, certolizumab pegol, etanercept, golimumab, or infliximab). The baseline period was the 6 months preceding the index date, which was used to ensure that patients were TNFi-naïve. The follow-up period began on the index date for each patient and lasted up to 2 years. Follow-up ended on the earliest date of: disenrollment from MarketScan, HIE outcome diagnosis date, discontinuation of TNFi therapy, end of study (June 30, 2014), or 2 years after index date.

TNFi exposure was based on time from index date until the patient discontinued use of TNFi medication. Patients were permitted to switch TNFi medication if there was no interruption in TNFi use without truncating the time of follow-up. Exposure to oral GCs was assessed during the follow-up period and was categorized as: no exposure, very low dose $(\leq 5.0 \mathrm{mg})$, low dose $(\leq 7.5 \mathrm{mg})$, high dose $(>7.5 \mathrm{mg})$, and very high dose $(>20 \mathrm{mg})$. A sensitivity analysis of a dose $\geq 10 \mathrm{mg}$ based on categories of low-dose and high-dose GCs as defined by the American College of Rheumatology (ACR) [10] was also performed. All steroid claims were converted to a $5 \mathrm{mg}$ prednisone equivalent dose. Patients could have multiple oral GC exposures and could contribute time to different GC exposure categories, including the "no exposure' category when they were off GCs. For example, a patient could have had several claims for varying low or high GC doses over the follow-up time, as well as intervals without GC claims. Each GC exposure was then allocated to the appropriate GC dose cohort and the time that patients were not receiving any GC was allocated to the no GC cohort. Cumulative episodic exposures for each dose cohort were measured. To accommodate the time required for drug clearance, the exposure time for high-dose exposures was extended an additional 3 days. If the patient transitioned directly from a high-dose to a low-dose GC, the low-dose exposure time was delayed by 3 days and the initial 3 days after the dose decrease were attributed to the high-dose GC. Exposure to other RA medications, such as nonbiologic DMARDs, was collected only during the baseline period.

\section{Patients}

Eligible patients were aged $\geq 18$ years and had a confirmed diagnosis of RA [International Classification of Diseases, Ninth Revision, Clinical Modification (ICD-9-CM) code 714.0] defined by one inpatient or one outpatient diagnostic claim accompanied by $\geq 1$ prescription for a TNFi medication within 30 days prior to and $\leq 365$ days after an RA claim date. Patients were required to have $\geq 12$ months of continuous enrollment with pharmacy coverage, which included the 6-month baseline period and at least 6 months of follow-up. Patients were excluded if they had a confirmed diagnosis of psoriasis, psoriatic arthritis, ankylosing spondylitis, and/or inflammatory bowel disease (other indications for TNFi medications), a confirmed diagnosis of HIV/AIDS, any malignancy (excluding nonmelanoma skin cancer), receipt of an organ transplant before index date, exposure to a TNFi medication during the baseline period, and any inpatient HIE diagnostic claim with one overnight hospitalization stay in which the HIE diagnosis was the primary or secondary reason for hospitalization during the 90 days preceding and including the index date.

\section{Study outcomes}

The rate of incident HIEs was estimated for each oral GC exposure group, for collective TNFi exposures, and for individual TNFi medication exposures. Rate ratios comparing the incidence rates of patients with low- and high-dose GC exposures were calculated. 


\section{Statistical considerations}

Incidence rates (IRs) of HIEs and 95\% CIs were calculated per 100 patient-years. Univariate and multivariable Poisson regression models were used to assess the association between TNFi exposure, oral GC exposure, demographics, baseline comorbidities, concomitant medications, and HIEs. Covariates with $P<0.20$ in univariate models were included in the initial multivariable model. Further evaluation was conducted to produce the most parsimonious model. Baseline demographics and clinical characteristics were based on GC category on the index date; categories were mutually exclusive at baseline.

\section{Results}

\section{Patients}

A total of 40,933 eligible patients were identified in the database. At baseline, the distribution was as follows: 28,867 patients $(70.5 \%)$ on no GC, $9011(22.0 \%)$ on lowdose GC, and 3055 (7.5\%) on high-dose GC. Within the low-dose GC cohort, a subset of 8632 were on very lowdose GC and within the high-dose GC cohort, 131 were on very high dose GC. Most patients were women (77.4\%), and the mean age was 53.0 [standard deviation (SD) 12.6] years (Table 1).

\section{IRs of HIEs}

HIE IRs were similar for all patients receiving lowdose GC $(\leq 7.5 \mathrm{mg})$ and the subset of patients with very

Table 1 Baseline demographic and clinical characteristics

\begin{tabular}{|c|c|c|c|c|c|}
\hline & $\begin{array}{l}\text { No GC } \\
N=28,867\end{array}$ & $\begin{array}{l}\text { Very low dose } \mathrm{GC}^{\mathrm{a}} \\
(\leq 5.0 \mathrm{mg}) \\
N=8632\end{array}$ & $\begin{array}{l}\text { Low-dose GC } \\
(\leq 7.5 \mathrm{mg}) \\
N=9011\end{array}$ & $\begin{array}{l}\text { High-dose GC } \\
(>7.5 \mathrm{mg}) \\
N=3055\end{array}$ & $\begin{array}{l}\text { Very high dose } \mathrm{GC}^{\mathrm{b}} \\
(>20.0 \mathrm{mg}) \\
N=131\end{array}$ \\
\hline Age, mean years & 52.5 & 54.2 & 54.3 & 53.4 & 51.6 \\
\hline \multicolumn{6}{|l|}{ Age category, $n(\%)$} \\
\hline$<65$ years & $25,606(88.7)$ & $7345(85.1)$ & $7642(84.8)$ & $2662(87.1)$ & $117(89.3)$ \\
\hline$\geq 65$ years & $3261(11.3)$ & $1287(14.9)$ & $1369(15.2)$ & $393(12.9)$ & $14(10.7)$ \\
\hline Sex, $n$ female $(\%)$ & $22,818(79.0)$ & $6459(74.8)$ & $6731(74.7)$ & $2130(69.7)$ & $91(69.5)$ \\
\hline \multicolumn{6}{|l|}{ Select comorbidities, $n(\%)$} \\
\hline Hypertension & $2,722(9.4)$ & $938(10.9)$ & $981(10.9)$ & $370(12.1)$ & $14(10.7)$ \\
\hline Diabetes & $1891(6.6)$ & $475(5.5)$ & $496(5.5)$ & $204(6.7)$ & $9(6.9)$ \\
\hline Congestive heart failure & $574(2.0)$ & $223(2.6)$ & $241(2.7)$ & $105(3.4)$ & $5(3.8)$ \\
\hline Asthma & $435(1.5)$ & $113(1.3)$ & $122(1.4)$ & $71(2.3)$ & $4(3.1)$ \\
\hline COPD & $375(1.3)$ & $178(2.1)$ & $191(2.1)$ & $80(2.6)$ & $7(5.3)$ \\
\hline Renal disease & $277(1.0)$ & $80(0.9)$ & $87(1.0)$ & $60(2.0)$ & $4(3.1)$ \\
\hline Peripheral vascular disease & $262(0.9)$ & $97(1.1)$ & $103(1.1)$ & $60(2.0)$ & $5(3.8)$ \\
\hline Exposure to injectable GC, $n(\%)$ & $9398(32.6)$ & $3025(35.0)$ & $3152(35.0)$ & $1214(39.7)$ & $49(37.4)$ \\
\hline Exposure to oral GC, $n(\%)$ & $12,240(42.4)$ & $8,475(98.2)$ & $8,851(98.2)$ & $3,021(98.9)$ & $129(98.5)$ \\
\hline Exposure to nonbiologic DMARD, $n(\%)$ & $22,097(76.5)$ & $7372(85.4)$ & $7701(85.5)$ & $2586(84.6)$ & $103(78.6)$ \\
\hline \multicolumn{6}{|l|}{ Exposure to biologic DMARD, $n(\%)$} \\
\hline Adalimumab & $9636(33.4)$ & $3086(35.8)$ & $3213(35.7)$ & $1066(34.9)$ & $48(36.6)$ \\
\hline Certolizumab pegol & $776(2.7)$ & $213(2.5)$ & $224(2.5)$ & $71(2.3)$ & $3(2.3)$ \\
\hline Etanercept & $13,052(45.2)$ & $3842(44.5)$ & 4009 (44.5) & $1366(44.7)$ & $55(42.0)$ \\
\hline Golimumab & $781(2.7)$ & $212(2.5)$ & $224(2.5)$ & $75(2.5)$ & $5(3.8)$ \\
\hline Infliximab & $4615(16.0)$ & $1279(14.8)$ & $1341(14.9)$ & 477 (15.6) & $20(15.3)$ \\
\hline HIEs, $n(\%)$ & $276(1.0)$ & $111(1.3)$ & $116(1.3)$ & $53(1.7)$ & $1(0.8)$ \\
\hline
\end{tabular}

Dose cohorts for demographic and clinical descriptions are based on status at index date and are mutually exclusive

$C O P D$ chronic obstructive pulmonary disease, DMARD disease-modifying antirheumatic drug, $G C$ glucocorticoid, HIEs hospitalized infectious events

${ }^{\text {a }}$ Very low dose GC cohort is a subset of the low-dose GC cohort

${ }^{\mathrm{b}}$ Very high dose GC cohort is a subset of the high-dose GC cohort 
low-dose GC $(\leq 5.0 \mathrm{mg})$, and increased with increasing GC dose (Table 2). IRs were higher for patients $\geq 65$ years of age in the no GC cohort and across all GC dose cohorts. A post hoc analysis of HIEs was conducted for the subset of patients receiving a very low GC dose $(<5 \mathrm{mg})$ compared with patients who received exactly $5 \mathrm{mg}$. These results were consistent with the trend showing decreased incidence of HIEs with decreasing dose: the IR per 100 patient-years (95\% CI) was $5.7(4.23-7.43)$ for patients who received $<5 \mathrm{mg} \mathrm{GC}$, and 6.7 (5.74-7.48) for patients who received exactly $5 \mathrm{mg} \mathrm{GC}$. A sensitivity analysis using a cut-off of $>10 \mathrm{mg}$ based on the ACR definition of high dose was also consistent with the GC dose relationship to HIEs: the IR per 100 patient-years $(95 \%$
CI) was 26.4 (20.40-32.33) for patients who received $>10 \mathrm{mg}$ GC. For patients aged $<65$ years and $\geq 65$ years, respectively, the IRs $(95 \% \mathrm{CI})$ were 22.5 (16.36-28.57) and 43.4 (25.67-61.16) for GC $>10 \mathrm{mg}$. There was a trend toward lower IRs with longer duration of GC exposure across all GC dose cohorts (Table 3). IRs for HIEs were generally similar across TNFi medications for patients receiving no GC and low-dose GC, although infliximab appeared to have the highest IRs for all GC dose cohorts (Fig. 1). For patients receiving high-dose GC, results were variable among the TNFi medications, possibly due to the relatively small number of patient-years of exposure for this GC dose cohort. The most common infections requiring hospitalization across all GC dose

Table 2 Summary of IRs of HIEs stratified by age group

\begin{tabular}{|c|c|c|c|c|c|}
\hline & No GC & $\begin{array}{l}\text { Very low dose } \mathrm{GC}^{\mathrm{a}} \\
(\leq 5.0 \mathrm{mg})\end{array}$ & $\begin{array}{l}\text { Low-dose GC } \\
(\leq 7.5 \mathrm{mg})\end{array}$ & $\begin{array}{l}\text { High-dose GC } \\
(>7.5 \mathrm{mg})\end{array}$ & $\begin{array}{l}\text { Very high dose } G^{b} \\
(>20.0 \mathrm{mg})\end{array}$ \\
\hline \multicolumn{6}{|l|}{ All ages } \\
\hline Total patient-years & $23,654.2$ & 4375.4 & 4603.1 & 1211.6 & 45.0 \\
\hline $\begin{array}{l}\text { IR per } 100 \text { patient-years } \\
\quad(95 \% \mathrm{CI})\end{array}$ & $\begin{array}{l}3.9 \\
(3.63-4.13)\end{array}$ & $\begin{array}{l}6.4 \\
(5.65-7.17)\end{array}$ & $\begin{array}{l}6.4 \\
(5.68-7.16)\end{array}$ & $\begin{array}{l}13.3 \\
(11.32-15.51)\end{array}$ & $\begin{array}{l}24.5 \\
(12.21-43.76)\end{array}$ \\
\hline \multicolumn{6}{|l|}{ Ages $<65$ years } \\
\hline Total patient-years & $20,085.2$ & 3463.1 & 3634.0 & 995.2 & 35.8 \\
\hline $\begin{array}{l}\text { IR per } 100 \text { patient-years } \\
\quad(95 \% \mathrm{CI})\end{array}$ & $\begin{array}{l}3.2 \\
(2.91-3.40)\end{array}$ & $\begin{array}{l}4.7 \\
(4.04-5.52)\end{array}$ & $\begin{array}{l}4.7 \\
(4.00-5.44)\end{array}$ & $\begin{array}{l}11.7 \\
(9.63-13.98)\end{array}$ & $\begin{array}{l}22.3 \\
(9.64-43.98)\end{array}$ \\
\hline \multicolumn{6}{|l|}{ Ages $\geq 65$ years } \\
\hline Total patient-years & $3,569.0$ & 912.3 & 969.1 & 216.4 & 9.1 \\
\hline $\begin{array}{l}\text { IR per } 100 \text { patient-years } \\
\quad(95 \% \mathrm{CI})\end{array}$ & $\begin{array}{l}8.0 \\
(7.06-8.94)\end{array}$ & $\begin{array}{l}12.6 \\
(10.41-15.13)\end{array}$ & $\begin{array}{l}12.8 \\
(10.64-15.26)\end{array}$ & $\begin{array}{l}20.8 \\
(15.17-27.83)\end{array}$ & $\begin{array}{l}32.9 \\
(6.77-95.99)\end{array}$ \\
\hline
\end{tabular}

$C I$ confidence interval, $G C$ glucocorticoid, $H I E$ hospitalized infectious event, $I R$ incidence rate

${ }^{\text {a }}$ Very low dose GC cohort is a subset of the low-dose GC cohort

${ }^{b}$ Very high dose GC cohort is a subset of the high-dose GC cohort

Table 3 Summary of IRs of HIEs stratified by follow-up time

\begin{tabular}{|c|c|c|c|c|}
\hline & 1-14 days follow-up & 15-29 days follow-up & 30-59 days follow-up & $\geq 60$ daysfollow-up \\
\hline \multicolumn{5}{|l|}{ No GC } \\
\hline No. of HIE cases (total patient-years) & $54(1,494.2)$ & $76(1515.7)$ & $122(2694.5)$ & $664(17,949.8)$ \\
\hline IR per 100 patient-years $(95 \% \mathrm{CI})$ & $3.6(2.71-4.72)$ & $5.0(3.95-6.28)$ & $4.5(3.76-5.41)$ & $3.7(3.42-3.99)$ \\
\hline Rate ratio $(95 \% \mathrm{CI})$ & Reference & $1.4(0.98-1.97)$ & $1.3(0.91-1.73)$ & $1.0(0.78-1.35)$ \\
\hline \multicolumn{5}{|l|}{ Low-dose GC } \\
\hline No. of HIE cases (Total patient-years) & $42(625)$ & $34(549.9)$ & $62(790.2)$ & $156(2,638.1)$ \\
\hline IR per 100 patient-years (95\% CI) & $6.7(4.84-9.08)$ & $6.2(4.28-8.64)$ & $7.9(6.02-10.06)$ & $5.9(5.02-6.92)$ \\
\hline Rate ratio $(95 \% \mathrm{CI})$ & Reference & $0.9(0.59-1.45)$ & $1.2(0.79-1.73)$ & $0.88(0.63-1.24)$ \\
\hline \multicolumn{5}{|l|}{ High-dose GC } \\
\hline No. of HIE cases (total patient-years) & $47(356.5)$ & $23(230.3)$ & $34(246.0)$ & $57(378.8)$ \\
\hline IR per 100 patient-years (95\% CI) & $13.2(9.69-17.53)$ & $10.0(6.33-14.99)$ & $13.8(9.57-19.32)$ & $15.1(11.4-19.5)$ \\
\hline Rate ratio $(95 \% \mathrm{CI})$ & Reference & $0.8(0.46-1.25)$ & $1.1(0.67-1.63)$ & $1.1(0.78-1.68)$ \\
\hline
\end{tabular}

$C I$ confidence interval, $G C$ glucocorticoid, $H I E$ hospitalized infectious event, $I R$ incidence rate 


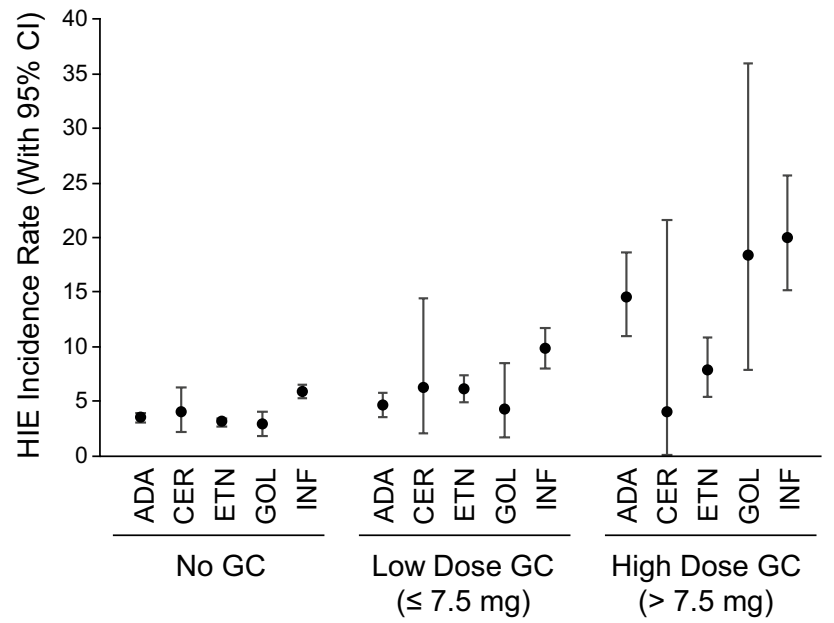

Fig. 1 Incidence rates of HIEs stratified by index TNFi medication. HIE incidence rates are shown for patients receiving TNFi medication exposed to no GC, low-dose GC, or high-dose GC. Error bars represent $95 \%$ CI. ADA adalimumab, CER certolizumab pegol, $C I$ confidence interval, $E T N$ etanercept, $G C$ glucocorticoid, $G O L$ golimumab, $H I E$ hospitalized infectious event, $I N F$ infliximab, $T N F i$ tumor necrosis factor inhibitor

cohorts were pneumonia, cellulitis/abscess, and septicemia (Table 4).

\section{Adjusted rate ratios for HIEs}

After controlling for variables of baseline GC dose, age, use of injectable or oral GCs, use of nonbiologic DMARDs, comorbidities (diabetes, asthma, renal disease, congestive heart failure, hypertension, peripheral vascular disease, and chronic obstructive pulmonary disease (COPD); assessed individually), baseline HIEs, and exposure to TNFi medications, the adjusted rate ratio (95\% CI) for low-dose GC vs no GC was 1.4 (1.19-1.58), for high-dose GC vs no GC was 2.8 (2.30-3.31), and for high-dose GC vs low-dose GC was 2.0 (1.65-2.44) (Table 5). These variables were also independent predictors of HIE risk for both low- and highdose GCs except for peripheral vascular disease, which was a predictor of HIE risk for only high-dose GCs. Infliximab was independently associated with a higher rate of infection among all steroid dose comparisons, while adalimumab was associated with a slight increase in the high-dose to no GC comparison.

\section{Discussion}

Rates of HIEs in this analysis of patients with RA were lowest for patients on no GC and increased with increasing dose of oral GCs. In a similar analysis of RA patients, the overall rate of infections requiring hospitalization was 9.6 cases per 100 person-years [1], compared with IRs of $3.9,6.4$ and 13.3 per 100 patient-years for patients on no GC, low-dose GC, and high-dose GC, respectively, in our study. Rates of HIEs were fairly similar across TNFi medications for each GC dose cohort; although patients on infliximab had consistently higher rates of HIEs in each GC dose cohort. These results are consistent with an analysis of data from the US Veterans Administration, in which rates of hospitalizations for bacterial infections were similar between adalimumab, and etanercept, and higher for infliximab [7]. Results from that study also showed that patients receiving doses of prednisone $>7.5 \mathrm{mg}$ /day were at increased risk of infection [7]. Data from the Canadian BioTRAC registry showed that RA patients treated with infliximab receiving GCs at a dose $>5 \mathrm{mg}$ were 2.48 times more likely to develop an infection than patients with no GC exposure [11].

The trend of GC-dose-dependent increased rates of infection has been reported previously. Dixon et al. showed that increases in GC dose led to increases in relative risk for infection, with relative risks of 2.5, 3.0, and 4.3 for GC doses of 5, 10, and $>20 \mathrm{mg}$, respectively [12]. RA therapies and treatment status (naïve or previously treated) were not reported, and the authors noted that adjustment for comorbidity and RA therapies led to estimates that were $~ 40 \%$ higher than the unadjusted estimates. Data from the German biologics register RABBIT showed that the IR ratios

Table 4 Most common infections requiring hospitalization

\begin{tabular}{|c|c|c|c|c|c|}
\hline Infection, $n$ patients ( $\%$ of HIEs) & No GC (916 HIEs) & $\begin{array}{l}\text { Very low dose GC } \\
(279 \text { HIEs })\end{array}$ & $\begin{array}{l}\text { Low-dose GC } \\
\text { (294 HIEs) }\end{array}$ & $\begin{array}{l}\text { High-dose GC } \\
\text { (161 HIEs) }\end{array}$ & $\begin{array}{l}\text { Very high } \\
\text { dose GC ( } 11 \\
\text { HIEs) }\end{array}$ \\
\hline Pneumonia (organism unspecified) & $181(19.8)$ & $59(21.2)$ & $64(21.8)$ & $31(19.3)$ & $3(27.3)$ \\
\hline Cellulitis/abscess & $101(11.0)$ & $31(11.1)$ & $31(10.5)$ & $16(9.9)$ & $1(9.0)$ \\
\hline Septicemia & $92(10.0)$ & $37(13.3)$ & $38(12.9)$ & $19(11.8)$ & $1(9.0)$ \\
\hline Pleurisy & $69(7.5)$ & $17(6.1)$ & $17(5.8)$ & & \\
\hline Disorders of urethra/urinary tract & $63(6.9)$ & $18(6.5)$ & $22(7.5)$ & $10(6.2)$ & $1(9.0)$ \\
\hline
\end{tabular}

HIEs hospitalized infectious events, $G C$ glucocorticoid, HIEs hospitalized infectious events 
Table 5 Adjusted rate ratios for HIEs for no GC, low-dose GC, and high-dose GC

\begin{tabular}{|c|c|c|c|c|c|c|}
\hline & \multicolumn{2}{|c|}{$\begin{array}{l}\text { Low-dose GC vs No } \\
\text { GC }\end{array}$} & \multicolumn{2}{|c|}{$\begin{array}{l}\text { High-dose GC vs No } \\
\text { GC }\end{array}$} & \multicolumn{2}{|c|}{$\begin{array}{l}\text { High-dose vs Low- } \\
\text { dose GC }\end{array}$} \\
\hline & $\mathrm{RR}$ & $95 \%$ CI & $\mathrm{RR}$ & $95 \%$ CI & $\mathrm{RR}$ & $95 \%$ CI \\
\hline Crude rate ratios & 1.7 & $1.45-1.88$ & 3.4 & $2.90-4.06$ & 2.2 & $1.78-2.61$ \\
\hline Adjusted rate ratios & $1.4^{\ddagger}$ & $1.19-1.58$ & $2.8^{\ddagger}$ & $2.90-4.06$ & $2.0^{\ddagger}$ & $1.65-2.44$ \\
\hline Age (continuous) & $1.0^{\ddagger}$ & $0.97-0.98$ & $1.0^{\ddagger}$ & $0.97-0.98$ & $1.0^{\ddagger}$ & $0.96-0.98$ \\
\hline Exposure to injectable GC & $1.3^{\ddagger}$ & $1.17-1.47$ & $1.3^{\ddagger}$ & $1.16-1.48$ & $1.3^{*}$ & $1.07-1.56$ \\
\hline Exposure to oral GC & $1.2^{*}$ & $1.09-1.42$ & $1.2^{*}$ & $1.07-1.40$ & 0.8 & $0.56-1.08$ \\
\hline Exposure to nonbiologic DMARD & $0.7^{\ddagger}$ & $0.64-0.86$ & $0.8^{*}$ & $0.67-0.91$ & $0.7^{*}$ & $0.53-0.86$ \\
\hline Diabetes & $1.5^{\ddagger}$ & $1.24-1.82$ & $1.7^{\ddagger}$ & $1.37-2.01$ & 1.1 & $0.82-1.58$ \\
\hline Asthma & $2.0^{\ddagger}$ & $1.42-2.73$ & $1.8^{\dagger}$ & $1.29-2.57$ & 1.1 & $0.65-2.04$ \\
\hline Renal disease & $1.7 *$ & $1.21-2.41$ & $1.7^{*}$ & $1.22-2.46$ & 1.4 & $0.86-2.37$ \\
\hline Congestive heart failure & $1.4^{*}$ & $1.08-1.83$ & $1.4^{*}$ & $1.08-1.88$ & 1.3 & $0.88-1.94$ \\
\hline Hypertension & $1.4^{\dagger}$ & $1.16-1.62$ & $1.3 *$ & $1.07-1.52$ & $1.5^{\dagger}$ & $1.18-1.93$ \\
\hline Peripheral vascular disease & 1.2 & $0.82-1.81$ & 1.4 & $0.97-2.14$ & $0.5^{*}$ & $0.22-0.93$ \\
\hline COPD & $2.0^{\ddagger}$ & $1.53-2.73$ & $2.0^{\ddagger}$ & $1.44-2.69$ & $2.2^{\ddagger}$ & $1.49-3.34$ \\
\hline HIE during baseline & $1.8^{\dagger}$ & $1.28-2.58$ & $1.6^{*}$ & $1.11-2.44$ & $2.0^{*}$ & $1.22-3.39$ \\
\hline Etanercept & \multicolumn{2}{|c|}{ Reference } & \multicolumn{2}{|c|}{ Reference } & \multicolumn{2}{|c|}{ Reference } \\
\hline Adalimumab & 1.1 & $0.91-1.23$ & $1.3^{*}$ & $1.07-1.47$ & 1.1 & $0.84-1.36$ \\
\hline Infliximab & $1.6^{\ddagger}$ & $1.38-1.84$ & $1.8^{+}$ & $1.50-2.05$ & $1.6^{\ddagger}$ & $1.29-2.06$ \\
\hline Golimumab & 0.9 & $0.62-1.28$ & 1.1 & $0.77-1.59$ & 1.2 & $0.71-2.10$ \\
\hline Certolizumab pegol & 1.1 & $0.73-1.74$ & 1.1 & $0.69-1.81$ & 0.8 & $0.37-1.92$ \\
\hline
\end{tabular}

$R R$ rate ratio, $G C$ glucocorticoid, $D M A R D$ disease-modifying antirheumatic drug, $C O P D$ chronic obstructive pulmonary disease, $C I$ confidence interval

$* P \leq 0.05$

${ }^{\dagger} P \leq 0.001$

${ }^{\ddagger} P \leq 0.0001$

$(95 \% \mathrm{CI})$ of infections in patients receiving a very high GC dose $(\geq 15 \mathrm{mg})$ or a high GC dose (7.5-14 mg) were 4.7 (2.4-9.4) and 2.1 (1.4-3.2), respectively, compared to patients with no GC exposure [13].

The ACR defines low-dose and high-dose GCs as $\leq 10 \mathrm{mg}$ and $>10 \mathrm{mg}$, respectively [10]. Based on this cut-off, we conducted a sensitivity analysis and found that the IR (95\% CI) for HIEs was 26.4 (20.4-32.33) per 100 patient-years for all patients receiving $>10 \mathrm{mg}$ and a notable 43.4 (25.67-61.16) for patients $\geq 65$ years of age. These results are consistent with findings from a study that was designed to identify risk factors for serious infections in RA patients. In that study, patients receiving a dose $>10 \mathrm{mg}$ were 3.97 times more likely to develop a serious infection compared to patients on no GC, and that patients aged $\geq 80$ years were at higher risk for developing an infection than patients aged $<80$ years (HR 2.18; 95\% CI 1.21-3.91) [14]. The high risk of infection needs to be considered when selecting a GC dose for elderly patients with RA.

Per the new ACR guidelines for the treatment of RA, combination therapy can be steroid sparing [10]. Our analysis showed that exposure to nonbiologic DMARDs during the baseline period was associated with a $20-30 \%$ reduction in HIE rate ratios. This finding could be due to better disease control with combination therapy or channeling of patients at high risk of infections away from combination therapy. Our analyses were not stratified by concomitant use of nonbiologic DMARD therapies throughout the follow-up period, and further research is required to address the impact of combination therapy on HIE rates.

Age was a strong predictor of HIE risk for both low and high GC doses. Additionally, comorbidities of diabetes, asthma, renal disease, congestive heart failure, hypertension, and COPD were strong predictors of HIE risk for low and high GC doses. Hypertension, peripheral vascular disease, and COPD were predictors of HIE risk for high-dose GC but not for low-dose GC. Among the individual TNFi treatments, infliximab was associated with a higher rate of infection at both the low- and highdose comparisons, consistent with other studies [8, 15]. Notably, the infliximab cohort was older than the other TNFi cohorts (data not shown), and a high proportion of patients $\geq 65$ years of age may have also contributed to the higher HIE rate for infliximab. This observation may be due in part to healthcare coverage for elderly patients: infused drugs such as infliximab are covered by Medicare 
Part B coverage whereas self-injected TNFi medications are not. Sample size was too small to allow for analyses by individual TNFi medications among those patients $>65$ years of age.

This study was unique in that it included the assessment of HIEs in patients newly initiating TNFi therapy, and also considered the duration of both TNFi and GC exposures and GC dose levels. A strength of the study was the amount of data available from the commercial claims database. The large patient population allowed for the evaluation of different dose levels and GC dose categories. The claims database also provides information on many variables (demographic, diagnostic, prescription claims for concurrent medications, etc.) that contributed to the analysis. The study also had some limitations. While underlying disease activity was not known, we did limit the analysis to patients who were newly initiating TNFi therapy and therefore expected to be comparable with relation to disease activity. Unmeasured confounding of disease severity is therefore a limitation of this study. TNFi exposure and oral GC dose levels were defined using administrative claims and pharmacy data, resulting in an inherent risk of misclassification error. Prednisone tapering may have occurred; however, based on limitations of the dataset, we were unable to identify when this occurred. Outpatient prescription claims used to identify therapies only indicated that a prescription was filled, but provided no information on actual utilization of the medication by the patient. A patient might not submit a reimbursement claim for a pharmacy-filled GC prescription, or might split doses to extend a prescription or to save cost; therefore, there is potential for misclassification of oral GC exposure status. The sample size was quite small for some subset analyses, particularly in the highdose category, and the results of those analyses should be interpreted with caution.

In conclusion, doses of oral GCs as low as $5 \mathrm{mg}$ were associated with an increased risk of infection in this cohort of RA patients. As with other subsets of the RA population, clinicians need to consider the steroid dose when evaluating the risk of infection among patients newly initiating TNFi therapies.

Acknowledgements We thank Dikran Toroser (Amgen Inc.) and Julia R. Gage (on behalf of Amgen Inc.) for assistance with writing the manuscript.

\section{Compliance with ethical standards}

Conflict of interest J. Schenfeld is a contract employee and received salary support from Amgen Inc. J. Iles, M. Trivedi, and N. Accortt are employees and shareholders of Amgen Inc.

Research involving human participants This article does not contain any studies with human participants performed by any of the auithors. For this type of study formal consent is not required.
Funding This study was sponsored by Immunex, a wholly owned subsidiary of Amgen Inc.

Open Access This article is distributed under the terms of the Creative Commons Attribution 4.0 International License (http:// creativecommons.org/licenses/by/4.0/), which permits unrestricted use, distribution, and reproduction in any medium, provided you give appropriate credit to the original author(s) and the source, provide a link to the Creative Commons license, and indicate if changes were made.

\section{References}

1. Doran MF, Crowson CS, Pond GR, O'Fallon WM, Gabriel SE (2002) Frequency of infection in patients with rheumatoid arthritis compared with controls: a population-based study. Arthritis Rheum 46(9):2287-2293. doi:10.1002/art.10524

2. Smitten AL, Choi HK, Hochberg MC, Suissa S, Simon TA, Testa MA, Chan KA (2008) The risk of hospitalized infection in patients with rheumatoid arthritis. J Rheumatol 35(3):387-393

3. Au K, Reed G, Curtis JR, Kremer JM, Greenberg JD, Strand V, Furst DE, Investigators C (2011) High disease activity is associated with an increased risk of infection in patients with rheumatoid arthritis. Ann Rheum Dis 70(5):785-791. doi:10.1136/ ard.2010.128637

4. Galloway JB, Hyrich KL, Mercer LK, Dixon WG, Fu B, Ustianowski AP, Watson KD, Lunt M, Symmons DP, Consortium BCC, British Society for Rheumatology Biologics R (2011) Anti-TNF therapy is associated with an increased risk of serious infections in patients with rheumatoid arthritis especially in the first 6 months of treatment: updated results from the British Society for Rheumatology Biologics Register with special emphasis on risks in the elderly. Rheumatology (Oxford) 50 (1):124-131. doi:10.1093/rheumatology/keq242

5. Grijalva CG, Kaltenbach L, Arbogast PG, Mitchel EF Jr, Griffin MR (2010) Initiation of rheumatoid arthritis treatments and the risk of serious infections. Rheumatology (Oxford) 49(1):82-90. doi:10.1093/rheumatology/kep325

6. Curtis JR, Xie F, Chen L, Muntner P, Grijalva CG, Spettell C, Fernandes J, McMahan RM, Baddley JW, Saag KG, Beukelman T, Delzell E (2012) Use of a disease risk score to compare serious infections associated with anti-tumor necrosis factor therapy among high- versus lower-risk rheumatoid arthritis patients. Arthritis Care Res (Hoboken) 64(10):1480-1489. doi:10.1002/ acr.21805

7. Curtis JR, Yang S, Patkar NM, Chen L, Singh JA, Cannon GW, Mikuls TR, Delzell E, Saag KG, Safford MM, DuVall S, Alexander K, Napalkov P, Winthrop KL, Burton MJ, Kamauu A, Baddley JW (2014) Risk of hospitalized bacterial infections associated with biologic treatment among US veterans with rheumatoid arthritis. Arthritis Care Res (Hoboken) 66(7):990 997. doi:10.1002/acr.22281

8. Atzeni F, Sarzi-Puttini P, Botsios C, Carletto A, Cipriani P, Favalli EG, Frati E, Foschi V, Gasparini S, Giardina A, Gremese E, Iannone F, Sebastiani M, Ziglioli T, Biasi D, Ferri C, Galeazzi M, Gerli R, Giacomelli R, Gorla R, Govoni M, Lapadula G, Marchesoni A, Salaffi F, Punzi L, Triolo G, Ferraccioli G (2012) Long-term anti-TNF therapy and the risk of serious infections in a cohort of patients with rheumatoid arthritis: comparison of adalimumab, etanercept and infliximab in the GISEA registry. Autoimmun Rev 12(2):225-229. doi:10.1016/j. autrev.2012.06.008 
9. Lane MA, McDonald JR, Zeringue AL, Caplan L, Curtis JR, Ranganathan P, Eisen SA (2011) TNF-a antagonist use and risk of hospitalization for infection in a national cohort of veterans with rheumatoid arthritis. Medicine (Baltimore) 90(2):139-145. doi:10.1097/MD.0b013e318211106a

10. Singh JA, Saag KG, Bridges SL Jr., Akl EA, Bannuru RR, Sullivan MC, Vaysbrot E, McNaughton C, Osani M, Shmerling RH, Curtis JR, Furst DE, Parks D, Kavanaugh A, O’Dell J, King C, Leong A, Matteson EL, Schousboe JT, Drevlow B, Ginsberg S, Grober J, St Clair EW, Tindall E, Miller AS, McAlindon T (2016) 2015 American College of Rheumatology guideline for the treatment of rheumatoid arthritis. Arthritis Rheumatol 68 (1):1-26. doi:10.1002/art.39480

11. Haraoui B, Jovaisas A, Bensen WG, Faraawi R, Kelsall J, Dixit S, Rodrigues J, Sheriff M, Rampakakis E, Sampalis JS, Lehman AJ, Otawa S, Nantel F, Shawi M (2015) Use of corticosteroids in patients with rheumatoid arthritis treated with infliximab: treatment implications based on a real-world Canadian population. RMD Open 1 (1):e000078. doi:10.1136/rmdopen-2015-000078

12. Dixon WG, Suissa S, Hudson M (2011) The association between systemic glucocorticoid therapy and the risk of infection in patients with rheumatoid arthritis: systematic review and metaanalyses. Arthritis Res Ther 13(4):R139. doi:10.1186/ar3453

13. Strangfeld A, Eveslage M, Schneider M, Bergerhausen HJ, Klopsch T, Zink A, Listing J (2011) Treatment benefit or survival of the fittest: what drives the time-dependent decrease in serious infection rates under TNF inhibition and what does this imply for the individual patient? Ann Rheum Dis 70(11):19141920. doi:10.1136/ard.2011.151043

14. Crowson CS, Hoganson DD, Fitz-Gibbon PD, Matteson EL (2012) Development and validation of a risk score for serious infection in patients with rheumatoid arthritis. Arthritis Rheum 64(9):2847-2855. doi:10.1002/art.34530

15. van Dartel SA, Fransen J, Kievit W, Flendrie M, den Broeder AA, Visser H, Hartkamp A, van de Laar MA, van Riel PL (2013) Difference in the risk of serious infections in patients with rheumatoid arthritis treated with adalimumab, infliximab and etanercept: results from the Dutch Rheumatoid Arthritis Monitoring (DREAM) registry. Ann Rheum Dis 72(6):895-900. doi:10.1136/annrheumdis-2012-201338 